\title{
Bireysel Farklılıklar Kapsamında Çevrimiçi Öğrenme Araştırmalarına İlişkin Sistematik Bir Derleme*
}

\section{A Systematic Review of Online Learning Researches in the Context of Individual Differences}

\begin{abstract}
Hale ILGAZ ${ }^{* *}$
Received: 17 March 2018

Review Article

Accepted: 15 September 2018

ABSTRACT: Online learning has been offering practical, efficient and effective solutions for reaching out big groups of learners in terms of learning and education. In these environments, where the participants have distinct properties, although the contents have been diversified, it has been represented with the assumption of ideal user. These environments consist many people who have very distinct properties from each other. Even if the presented content has been diversified, mostly it is designed for the ideal user. However, every person has some individual characteristics, which can be natal and acquired in time. These individual differences are important in order to provide effective learning experiences in learning environments. In this context when the e-learning studies analyzed it can be seen that there are several studies, which focused on individual differences. In these studies, the effects of the variables such as personal traits, cognitive characteristics, and prior learning experiences on individuals' academic success, motivation, participation levels, and staying on system, and the relationships had been analyzed. The main objective of this study is conducting a systematic review with the aim of identifying which individual differences studied and their relationships with other variables between 2010-2017 years. In this context, researcher defined review criteria (keywords, selection criteria, method) and conducted review process. According to search results, 38 research articles have been included in this study. Prominent results show that cognitive differences have been worked less in comparison with the other variables in terms of individual differences perspective, while the most worked variables are demographic variables and personal traits.
\end{abstract}

Keywords: individual differences, e-learning, systematic review.

ÖZ: Çevrimiçi öğrenme aynı anda büyük kitlelere ulaşmada, eğitim-öğretim faaliyetleri yürütmede etkili, hızlı ve verimli çözümler sunabilmektedir. Birbirinden farklı özelliklere sahip katılımcıların bulunduğu bu ortamlarda bireylere çeşitlendirilmiş olsa da ideal kullanıcı varsayımına göre içerik türleri sunulmaktadır. Oysaki her birey doğuştan getirdiği ve sonradan kazandığı bir takım özelliklere sahiptir. Bu bireysel farklılıklar da öğrenme ortamlarında etkili öğrenme deneyimleri sağlayabilmek adına önemlidir. Bu bağlamda alanyazın incelendiğinde de bireysel farklılıkları odağına alan birçok e-öğrenme çalışması olduğu görülmektedir. Bu çalışmalarda kişilik özellikleri, bilişsel özellikler, geçmiş öğrenme deneyimleri gibi sıralanabilen bu değişkenlerin bireylerin akademik başarılarına, motivasyonlarına, katılım düzeylerine ve sistemde kalmalarına olan etkileri ve aralarındaki ilişkiler incelenmiştir. Bu çalışmanın temel amacı sistematik bir alanyazın taraması gerçekleştirilerek, 2010-2017 yılları arasında yayınlanan çalışmalara konu olan bireysel farklılıkların belirlenmesi ve bu farklılıkların hangi değişkenlerle incelendiğinin ortaya konulmasıdır. Bu kapsamda belirlenen alanyazın tarama kriterlerine göre (anahtar kelimeler, seçim kriterleri, yöntem) ISI Web of Knowledge, Ebscohost, Scopus ve JSTOR veritabanlarında taramalar gerçekleştirilmiş olup 38 makale çalışmaya dahil edilmiştir. Öne çıkan bulgular bireysel farklılıklar bağlamında bilişsel özelliklerin diğer değişkenlere oranla daha az incelendiğini gösterirken en fazla incelenen değişkenlerin demografik değişkenler ve kişilik özellikleri oldukları bulunmuştur.

Anahtar kelimeler: bireysel farklılıklar, e-öğrenme, sistematik derleme.

\footnotetext{
* This submission's abstract has been presented in ICITS 2017 Symposium and not published.

** Dr., Ankara University, Ankara, Turkey, hilgaz@ankara.edu.tr
}

Citation Information

Ilgaz H. (2018). Bireysel farklılıklar kapsamında çevrimiçi öğrenme araştırmalarına ilişkin sistematik bir derleme. Kuramsal Eğitimbilim Dergisi [Journal of Theoretical Educational Science], 11(4), 1003-1018. 


\section{Giriş}

Uzaktan eğitim tüm dünyada gittikçe yaygınlaşan ve beraberinde kendine ait bir pazar da yaratmış bir alandır. Uzaktan eğitimin büyüme hızını yansıtması açısından sunulan rakamlar bu hızlı büyümenin devam edeceğini göstermektedir. 2010 y1lında pazar payının 32 milyon dolar, 2015 yılında 107 milyon dolarla tanımlandığı uzaktan eğitimin 2025 dolaylarında 331 milyon dolarlık bir pazara hakim olmas1 öngörülmektedir (Accuray Research LLP, 2017).

$\mathrm{Bu}$ büyümenin sadece nicelikte değil nitelikte olması verilen eğitimin amacına ulaşmasına sağlayacaktır. Uzaktan eğitimdeki bu büyümeye paralel olarak öğrencilerin sistemi terk etme oranlarında artışlar kurumsal bazda rapor edilmekle birlikte araştırmalarda da mercek altına alınan önemli konulardan birisidir (Lee \& Choi, 2011; Levy, 2007; Park \& Choi, 2009). Terk etme davranışının birçok nedeni olduğu araştırmalarca ortaya konulmuştur. Etkili ve sürekli destek eksikliği (Nawrot \& Doucet, 2014; Poll, Widen \& Weller, 2014), fiziksel uzaklik ve sosyal izolasyon (Cho, Demei \& Laffey, 2010; Rovai, 2001; Schaeffer \& Konetes, 2010; Sun \& Rueda, 2012), teknik destek eksikliği (Clay, Rowland \& Packard, 2009) bunlar arasında görülmektedir. Ders kalitesi ve öğretim tasarımı da terk etme davranışında etkili olarak ortaya çıkan bir diğer faktördür (Ivankova \& Stick, 2007).

Öğretim tasarımı süreci eğitimin her türünde olduğu gibi uzaktan eğitimde de çok önemli bir role sahiptir. Özellikle tek seferde geleneksel bir yöntemle ulaşamayacağınız kadar sayıda katılımcıya ulaşma imkanı tanıması, kitle eğitimi yapılmasından dolayı tasarım sürecini doğru planlamak önemlidir. Her bir katılımcıya ayrı ayrı ulaşıp farklı bir tasarım sunmak da e-öğrenmede maalesef zaman ve uygulama açısından yüksek maliyetli bir sistem olmasından dolayı oldukça zordur. Öğretim tasarımı modellerinin çoğunluğunda hedef kitlenin tanınması sürecin ilk basamakları arasında yer almaktadır. Her bireyin kendine has özellikleri olmasına rağmen kitlelere sunulan eğitimlerde grubun genel olarak özellikleri ve ihtiyaçları dikkate alınmalıdır.

$\mathrm{Bu}$ tasarım sürecinde bireyleri birbirinden ayıran, aralarında bir fark yaratan her değişken bireysel farklılık olarak ele alınabilmektedir. Her bir birey farklı beceri, yetenek, ihtiyaç ve ilgileri de beraberinde getirmektedir dolayısıyla hem örgün hem uzaktan eğitim süreçlerinde bu özelliklere olabildiğince cevap verebilmek önemlidir (Norwich, 2002). Yaş, cinsiyet, bilişsel ya da öğrenme stilleri, deneyim, kişilik özellikleri, zeka, ön bilgi değişkenleri bunlar arasındadır. Özellikle gözlemlenemeyen psikolojik yapıların ölçülmesi, tespitlerinin zor olmasından ve bu değişkenlerin birbirlerini de etkiliyor olmalarından dolayı bireysel farklılıklar her daim önemli konuların başında gelmektedir (Riding, 2005). Aslında her çalışmada bağımlı ya da bağımsız olarak ele alınabilmekte olan bu değişkenlerin çalışmalar içerisinde nasıl konumlandırıldıkları önemlidir.

$\mathrm{Bu}$ çalışmanın temel amacı uzaktan eğitim alanında sistematik bir alan yazın taraması gerçekleştirerek, 2010-2017 yılları arasında yayınlanan çalışmalara konu olan bireysel farklılıkların belirlenmesi ve bu farklılıkların hangi değişkenlerle incelendiğinin ortaya konulmasıdır. Çalışmalarda bireysel farklılıklara hangi perspektiften bakıldığını ortaya koymak amaçlanmıştır. Bu nedenle de bireysel farklılıkları çalışmalarının odağında yer alan araştırmalar dahil edilmiştir. 


\section{Araştırma Soruları}

$\mathrm{Bu}$ araştırma kapsamında yanıt aranan sorular şu şekildedir:

1. E-öğrenme ortamlarında bireysel farklılıkları araştıran ve 2010-2017 yılları arasında yayınlanan çalışmalarda hangi araştırma desenleri kullanılmıştır?

2. E-öğrenme ortamlarında bireysel farklılıklar 2010-2017 y1lları arasında hangi bağımsız değişkenlerle incelenmiştir?

3. E-öğrenme ortamlarında bireysel farklılıkları araştıran çalışmalarda yer alan bağımlı değişkenler nelerdir?

4. E-öğrenme ortamlarında bireysel farklılıkları araştıran çalışmaların ülke profilleri nedir?

\section{Yöntem}

$\mathrm{Bu}$ araştırmada e-öğrenme alanında yapılan çalışmaları bireysel farklılıklar açısından incelemek amacıyla sistematik derleme yöntemi kullanılmıştır. Sistematik derleme yöntemi, araştırma sorularına cevap vermek adına önceden tanımlanan kriterler çerçevesinde veri toplamayı kapsamaktadır. Yanlılı̆̆ en aza indirgemek için açık, sistematik yöntemleri kullanır ve böylece daha güvenilir bulgular üretilmesine olanak tanır. Sistematik bir derlemenin temel özellikleri; çalışmalar için önceden belirlenen kriterlerle açık bir şekilde oluşturulmuş hedeflerinin olması, net ve tekrar edilebilir bir yöntem olması, belirlenen kriterleri sağlayan tüm araştırmaları tanımlamaya yönelik olması, araştırmaya konu olan çalışmaların bulgularının geçerliliğini değerlendirmesi, araştırmaya konu olan çalışmaların bulgularının ve özelliklerinin sistematik bir sunumunu ve sentezini sağlaması olarak sıralanabilir (Higgins \& Green, 2009). Bu çalışmada güvenilirliği sağlamak için araştırmacının dışında iki farklı araştırmacı tarafından makalelerin dahil edilme/edilmeme süreçleri kontrol edilmiş olup uyumsuz çıkan durumlar yeniden gözden geçirilmiştir.

\section{Tarama ve Eleme Kriterleri}

Bu kapsamda ISI Web of Knowledge (SSCI, ESCI, AHCI, SCI-Expanded), Ebscohost (Academic Search Complete, ERIC), Scopus, ve JSTOR veritabanlarında tarama işlemi yapılmıştır. Bu veritabanları eğitim teknolojileri, uzaktan eğitim ve eöğrenme alanlarını kapsayan çalışmaları içerdikleri için çalışmaya dahil edilmişlerdir. Çalışmaya sadece hakemli dergilerde yayınlanan çalışmalar dahil edilmiş olup, gri literatür kaynakları olarak tanımlanan tezler, teknik raporlar, kurumsal raporlar, bildiri metinleri, çalışma analizleri (Higgins \& Green, 2009) dahil edilmemiştir. Ayrıca yöntem olarak araştırma makalesi olmayanlar da (meta analiz, sistematik derleme gibi) araştırmaya dahil edilmemiştir. Taranan çalışmaların yayın yılı 2010-2017 yılları olarak belirlenmiştir. Uluslararası veritabanları kullanıldığı için yayın dili İngilizce olmayan çalışmalar araştırmaya dahil edilmemiştir. Tarama için seçilen anahtar kelimeler "individual differences"/"learner characteristic" + "e-learning", "web based learning", "online learning", ve "distance education" olarak belirlenmiştir.

Yapılan tarama işlemi sonucunda toplam 887 adet çalışmaya erişilmiştir. İlk aşamada taramalar sonucu birden fazla veritabanında kaydı çıkan çalışmalar temizlenmiştir. $\mathrm{Bu}$ işlem sırasında 377 çalışma silinerek 510 çalışma üzerinden ikinci eleme işlemine başlanmıştır. Bu aşamada ise SSCI, ESCI, AHCI, SCI-Expanded indekslerinde bulunmayan çalışmaların halen sonuçlar arasında yer aldığı görülmüştür 
ve bunlarla birlikte, derleme, yazılım ve ölçme aracı geliştirme türünde olan çalışmalar araştırma dışı bırakılmıştır. Bu işlem sonrasında ise 510 çalışmadan 447 tanesi elenmiş ve 63 çalışma ile araştırmaya devam edilmiştir. Çalışmaların detaylı incelenmesi aşamasında ise bireysel farklılıklara odaklanmayan 25 çalışma elenmiş ve son olarak 38 çalışma üzerinden analizler yapılmıştır Şekil 1'de çalışma sürecine ilişkin aşamalar gösterilmektedir.

Şekil 1. Sistematik Tarama Süreci

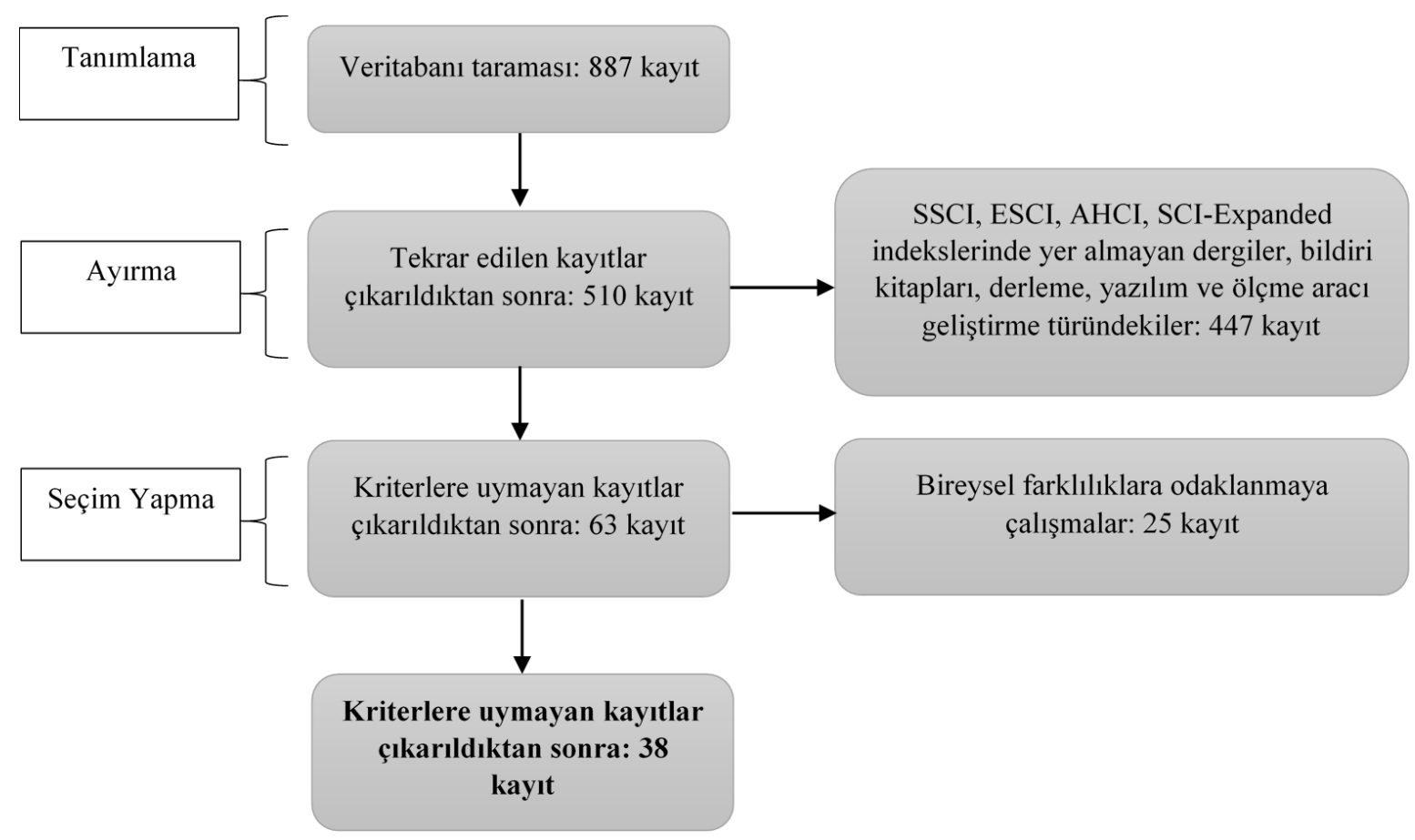

\section{Bulgular}

$\mathrm{Bu}$ araştırmaya dahil edilen 38 çalışmanın yayın yıllarına göre dağılımları Şekil 2'de yer almaktadır. Bu şekle göre 2014 ve 2011 yıllarında 7 çalışma yayınlanmıştır.

Şekil 2. Y1llara Göre İncelenen Makale Sayıları

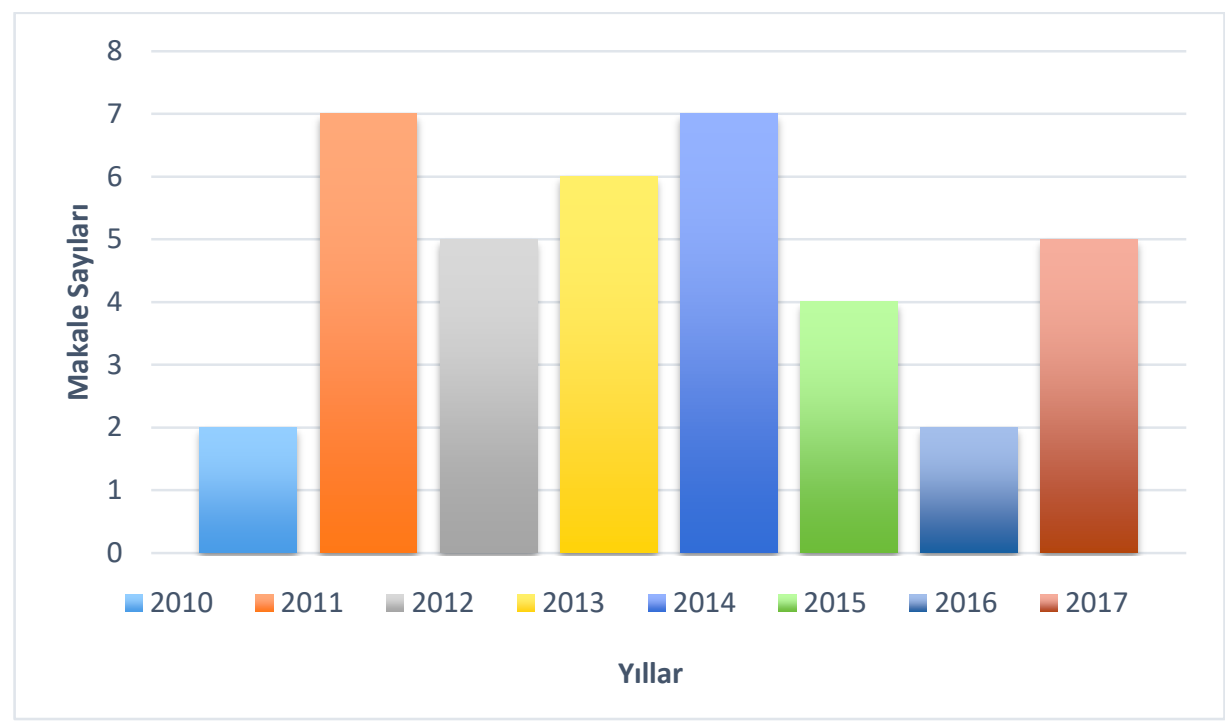




\section{Desenlerine Göre Araştırmalar}

Çevrimiçi öğrenme ortamlarında bireysel farklılıkları araştıran ve 2010-2017 yılları arasında yayınlanan çalışmalarda kullanılan araştırma yöntemlerine bakıldığında nicel çalışmaların karma çalışmalara oranla çok daha fazla tercih edildiği bulunmuştur. Çalışmalardan 37 tanesinin nicel araştırma desenine göre yürütüldüğü 1 adet çalışmanın ise hem nicel hem nitel yani karma araştırma desenine göre yürütüldüğü bulunmuştur. Araştırma desenlerine göre çalışmaların oranını Şekil 3'te yer almaktadır.

Şekil 3. Desenlerine Göre Çalışmalar

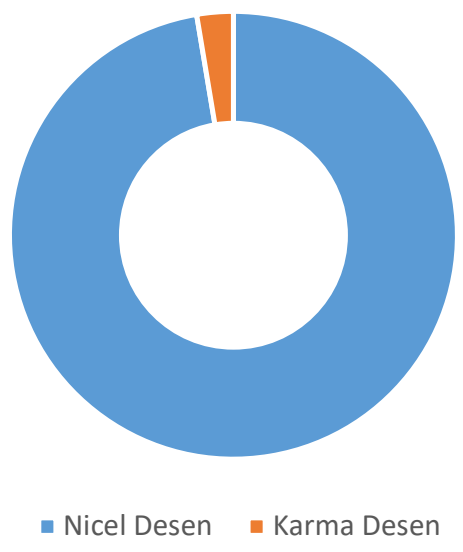

Nicel desenin kullanıldığı araştırmalarda ilişkisel araştırma yöntemleri $(n=24)$ en fazla tercih edilen yöntem olarak karşımıza çıkarken; bunu deneysel araştırma yöntemleri $(n=12)$ ve betimsel araştırma yöntemlerinin $(n=1)$ takip ettiği bulunmuştur. İlk tarama sonucunda elde edilen çalışmalar içerisinde nitel ve karma desenle yürütülen çalışmaların yer aldığı gözlemlenmiştir ancak bu çalışmaların bireysel farklılıklara odaklanmadıkları için ve yayın türü kriterlerine uymadıkları için analizler dışında bırakılmışlardır. Dolayısıyla kriterler kapsamında yapılan incelemede nicel çalışmaların görece fazla olması dikkat çekici bir bulgudur.

\section{Bağımsız Değişkenlere Göre Araştırmalar}

Araştırmalarda yazarlar tarafından ele alınan bağımsız değişkenlerin çoğunlukla cinsiyet, kişilik özellikleri, ön bilgi, bilişsel stil ve yaş olarak sıralandığı belirlenmiştir. İncelenen araştırmalarda yer alan bağımsız değişkenlerin kullanımlarına ilişkin veriler Tablo 1'de sunulmuştur.

En sık kullanılan bağımsız değişken olarak cinsiyet ön plana çıkmaktadır. Kapsam, yöntem fark etmeksizin çalışmaların çoğunluğunda katılımcı grubuna ilişkin tanımlamaların yapılmasında sıklıkla kullanılan cinsiyet değişkeninin bireysel farklılıklar bağlamında da araştırmalarda yer aldığı görülmektedir. Bu değişkeni kişilik özellikleri, ön bilgi, bilişsel stiller, öğrenme stilleri, yaş, öz yeterlik ve deneyim değişkenleri takip etmektedir. Kontrol odağı değişkeni ile içsel ya da dişsal kontrol odaklı bireyler (Gökçearslan \& Alper, 2015; Hsia, Chang \& Tseng, 2014); zamansallık değişkeni ile sabah ya da akşam çalışma tercihi gösteren bireyler (Randler, Horzum \& Vollmer, 2014) özelliklerine göre incelenmişlerdir. 
Tablo 1

Bă̆ımsız Değişkenlerin Türleri ve Kullanım Sıklıkları

\begin{tabular}{|c|c|c|c|c|c|}
\hline \multirow{2}{*}{ Değişken } & \multicolumn{2}{|c|}{ Kullanım Durumu } & \multirow{2}{*}{ Değişken } & \multicolumn{2}{|c|}{ Kullanım Durumu } \\
\hline & $\mathrm{f}$ & $\%$ & & $\mathrm{f}$ & $\%$ \\
\hline Cinsiyet & 10 & 16,13 & Kayg1 & 2 & 3,23 \\
\hline Kişilik özellikleri & 8 & 12,90 & Eğitim düzeyi & 2 & 3,23 \\
\hline Ön bilgi & 6 & 9,68 & İlgi & 1 & 1,61 \\
\hline Bilişsel stil & 5 & 8,06 & Zamansallık & 1 & 1,61 \\
\hline Yaş & 5 & 8,06 & Öz düzenleme becerisi & 1 & 1,61 \\
\hline Deneyim & 4 & 6,45 & Uzamsal beceriler & 1 & 1,61 \\
\hline Öz yeterlik & 4 & 6,45 & Zeka & 1 & 1,61 \\
\hline Öğrenme stili & 4 & 6,45 & Duygular & 1 & 1,61 \\
\hline Kontrol odağı & 2 & 3,23 & Dikkat & 1 & 1,61 \\
\hline Motivasyon & 2 & 3,23 & Bellek performansı & 1 & 1,61 \\
\hline
\end{tabular}

\section{Bağımlı Değişkenlere Göre Araştırmalar}

Araştırmalarda yazarlar tarafından ele alınan bağımlı değişkenler arasında başarı değişkenin oldukça sıklıkla kullanıldığ e-öğrenme kabulü, alg1, kaygı değişkenleri izlemektedir. İncelenen araştırmalarda yer alan bağımlı değişkenlerin kullanımlarına ilişkin veriler Tablo 2'de sunulmuştur.

Tablo 2

Bă̆ımlı Değişkenlerin Türleri ve Kullanım Sıklıkları

\begin{tabular}{|c|c|c|c|c|c|}
\hline \multirow{2}{*}{ Değişken } & \multicolumn{2}{|c|}{ Kullanım Durumu } & \multirow{2}{*}{ Değişken } & \multicolumn{2}{|c|}{ Kullanım Durumu } \\
\hline & $\mathrm{f}$ & $\%$ & & $\mathrm{f}$ & $\%$ \\
\hline $\begin{array}{l}\text { Akademik başarı, } \\
\text { ögrenme }\end{array}$ & 19 & 38,78 & Motivasyon & 1 & 2,04 \\
\hline Memnuniyet & 5 & 10,20 & Bilgi yapılandırmas1 & 1 & 2,04 \\
\hline e-Öğrenmeyi kabul & 3 & 6,12 & Kalıcılık & 1 & 2,04 \\
\hline Alg1 & 3 & 6,12 & Belirsizlik algis1 & 1 & 2,04 \\
\hline Kayg1 & 3 & 6,12 & Katılım & 1 & 2,04 \\
\hline Kullanım davranışları & 2 & 4,08 & Gönüllülük & 1 & 2,04 \\
\hline Adaptasyon & 1 & 2,04 & Etkileşim & 1 & 2,04 \\
\hline $\begin{array}{l}\text { Algılanan kullanım } \\
\text { kolaylığı }\end{array}$ & 1 & 2,04 & Bilişsel yük & 1 & 2,04 \\
\hline Tutum & 1 & 2,04 & $\begin{array}{l}\text { Problem çözme } \\
\text { performans1 }\end{array}$ & 1 & 2,04 \\
\hline Topluluk hissi & 1 & 2,04 & Yaratıcılık & 1 & 2,04 \\
\hline
\end{tabular}


Tablo 2'de de görüldüğü üzere "başarı” değişkeni diğer değişkenlere oranla daha sık kullanılan bir değişken olduğu ortaya çıkmıştır (Gökçearslan \& Alper, 2015; Granić \& Adams, 2011; Raes, Schellens, De Wever \& Vanderhoven, 2012). Teknoloji kabul kuramları bağlamında da e-öğrenmeyi kabul (Sanchez-Franco, Peral-Peral \& VillarejoRamos, 2014; Tarhini, Hone \& Liu, 2014) kullanım davranışları (Chen, 2010; Keller \& Karau, 2013) araştırmalarda sıklıkla kullanılan diğer değişkenlerdendir. Teknoloji kabul kuramına ek olarak topluluk hissi modeli bileşenleri (Gökçearslan \& Alper, 2015) çalışmalarda ayrı ayrı incelenen kuramsal yapılardandır.

\section{Ülkelere Göre Araştırmalar}

Çalışma kapsamında incelenen araştırmaların yürütüldüğü ülke profillerine ilişkin bilgiler Tablo 3'te yer almaktadır.

Tablo 3

Çalışmaların Yürütüldükleri Ülkeler

Ülke

Makaleler

\begin{tabular}{lcc} 
& $\mathrm{f}$ & $\%$ \\
\hline ABD & 9 & 23,08 \\
Tayvan & 8 & 20,51 \\
İngiltere & 3 & 7,69 \\
Türkiye & 3 & 7,69 \\
İspanya & 2 & 5,13 \\
Diğer ülkeler & 14 & 35,90
\end{tabular}

Çalışmaların ABD ve Tayvan da yoğunlaştığı görülmektedir. Diğer ülkeler arasında Avustralya, Belçika, Çin, Filistin, Hollanda, Irak, İran, Kanada, Kolombiya, Kuveyt, Lübnan, Şili, Umman ve Yeni Zelanda birer çalışma ile yer almaktadır.

Şekil 4. Ülkelere Göre Çalışmalar

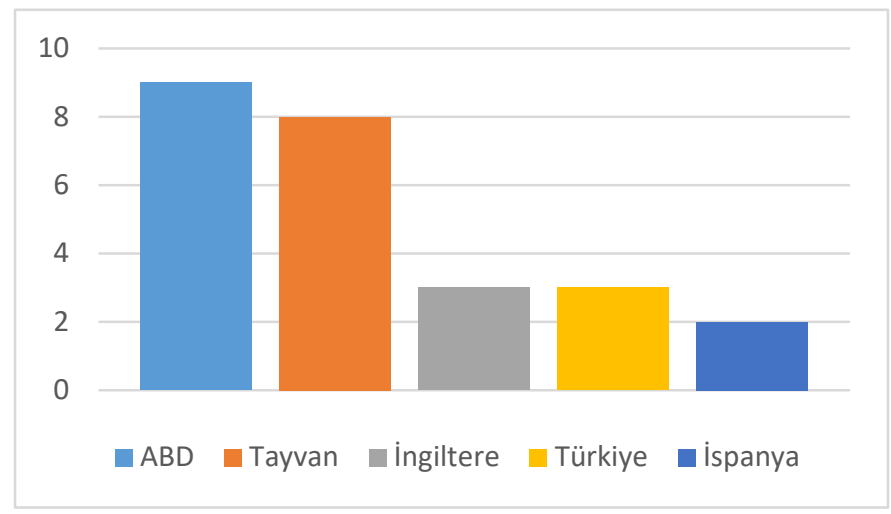




\section{Sonuçlar}

Literatür taraması sonucunda elde edilen çalışmalar incelendiğinde bireysel farlılıklar perspektifinin birçok açıdan ele alındığı görülmüştür. Akademik başarı, motivasyon, memnuniyet, kişilik özellikleri, teknoloji kabul, performans en çok araştırılan değişkenler olarak öne çıkmaktadır. Bunlara ek olarak zeka, uzamsal beceriler, duygular, ilgi, bellek performansı ve topluluk hissi de araştırmalarda yer alan değişkenler arasındadır. Bireysel farklılıkların üzerinde etkisine en fazla bakılan değişkenin de akademik başarı değişkeni olduğu ortaya çıkmaktadır. Bu sonuç aslında çok şaşırtıcı olmamakla birlikte ileride de bu şekilde olması beklenen bir durumdur. Öğrenme ortamlarına yapılan her müdahalenin, her araştırmanın temel amacı daha iyi öğrenme deneyimleri sağlamak, daha etkili öğrenmeler oluşturabilmek olmasından dolayı akademik başarı her zaman incelenmesi beklenen değişkenler arasındadır. Başarı değişkeni üzerinde yapılan araştırmalardan elde edilen verilere öğrenme ortamlarının ve süreçlerinin tasarımında dikkat edilmesi halinde daha etkili sonuçlar elde edilmesi beklenebilir.

Kişilik değişkeninin e-öğrenme ile ilgili çalışmalarda bireysel farklılıklar bağlamında en sık ele alınan değişken olduğu belirlenmiştir. Bu bağlamda incelenen çalışmalarda Beş Faktör Kişilik Modeli'nin ve Myers-Briggs Kişilik Modeli'nin temel alındığı bulunmuştur. McCrea ve Costa'nın (1987) geliştirdiği Beş Faktör Kişilik Modeli'ne göre dişadönüklük, nevrotizm, deneyime açıklık, uyumluluk ve öz-disiplin olmak üzere beş kişilik türü bulunmaktadır. Bu kapsamda incelenen çalışmalarda kişilik özelliklerinin boyutlarına göre kaygı (Keller \& Karau, 2013), gönüllülük (Randler ve diğerleri, 2014), belirsizlik hissi (Jraidi \& Frasson, 2013), memnuniyet (Sanchez-Franco ve diğerleri, 2014), başarı (Ghorbani \& Montazer, 2015; Granić \& Adams, 2011; Orvis, Brusso, Wasserman \& Fisher, 2011) değişkenleri ile aralarındaki ilişkiler incelenmiştir.

Öz yeterlilik bireysel farklılıklar bağlamında önemli bir yere sahiptir. Bireylerin davranışlarını, bilgisayar kullanma becerilerini, inançlarını ve kullanım durumlarını belirlemede öz yeterlilikler etkilidir ve bilgisayar öz yeterliliği kullanımı doğrudan etkileyen bir değişken olduğundan öğrenme süreçlerine etkisinin de bu paralelde olması beklenmektedir (Jashapara \& Tai, 2011). Bu bağlamda incelenen araştırmalarda bilgisayar ve e-öğrenme öz yeterliliğinin davranışsal niyet ve algılanan kullanım kolaylığı, kullanışlılık gibi teknoloji kabul modeli bileşenleriyle aralarında anlamlı ve pozitif ilişkiler olduğu belirlenmiştir.

E-öğrenme araştırmalarında bilişsel stillerin ve öğrenme stillerin de sıklıkla kullanıldığı görülmektedir. Araştırmaların bir kısmında bilişsel ve öğrenme stillerinin aynı yapıyı kapsadıkları ifade edilse de alan yazın incelendiğinde bu iki yapının birbirinden farklılaştığı görülmektedir. Bilişsel stil, bilgiyi işleme ve organize etme süreçlerinde bireyler tercih ettiği yollar olarak tanımlanırken (Price, 2014); öğrenme stili bireylerin öğrenme ortamı ya da materyale karşı olan tutumlarını kapsamaktadır ve görevden göreve değişiklikler gösterebilmektedirler (Deborah, Baskaran \& Kannan, 2014). Bu çalışma kapsamında incelenen çalışmalarda bilişsel stiller, alan bağımlı alan bağımsız ve bütüncül-sıralayıcı olarak ele alınmıştır. Öğrenme tercihleri ve öğrenme ile ilişkilerin incelendiği çalışmalarda bireylerin öğrenme tercihlerinde farklılıklaşmaların olduğu raporlanmıştır. Öğrenme stilleri bağlamında FelderSilverman öğrenme stilleri modeli ve Kolb’un öğrenme stilleri modellerinin kullanıldığı bulunmuştur. Felder-Silverman öğrenme stilleri modeli algısal - sezgisel, görsel - sözel, 
aktif - yansitıcı ve aşamalı - bütünsel olmak üzere 4 boyutludur (Felder \& Silverman, 1988). Kolb' un öğrenme stilleri modelinde ise 4 boyut bulunmaktadır. Bunlar; somut yaşantı, yansitıcı gözlem, soyut kavramsallaştırma ve aktif yaşantıdır (Kolb, 1984). Öğrenme stillerine getirilen eleştirilerin yoğunlaşmasına rağmen yapılan araştırmalarda halen etkileri araştırılan değişkenlerden olduğu görülmektedir. Tercih edilen öğrenme yolunun en etkili öğrenme yolunun iyi bir yordayıcısı olmaması; literatürde çok fazla sayıda tanımlanmış öğrenme stilinin bulunuyor olması; her bireyin kendine has özellikleri olmasından dolayı her bireye ait farklı bir stil tanımlaması yapılabilmesi öğrenme stillerine getirilen eleştiriler arasındadır (Kirschner \& van Merriënboer, 2013).

Demografik değişkenler eğitim araştırmalarında sıklıkla incelenen değişkenlerdendir. $\mathrm{Bu}$ araştırma kapsamında belirlenen kriterlerle yapılan analiz sonucunda da demografik özelliklerin incelendiği çalışmalara erişilmiştir. Bu durum bu değişkenlerin halen ön planda oldukları göstermektedir. Bu değişkenlere ilişkin alanyazında çok sayıda çalışma olmasından dolayı ve farklı yönlere odaklanılması önerilebilir.

Bellek, dikkat, uzamsal beceriler gibi bilişsel farklılıkları gözeten çalışma sayısının diğerlerine oranla daha az olduğu görülmektedir. Farklı özelliklere sahip bireylere tek tip ideal kullanıcı modeline göre ortamların tasarlanması her birey için aynı sonucu ortaya koymayacaktır. Bu nedenle bireylerin bu bilişsel özelliklerinden kaynaklanan varyasyonun bilinerek öğrenme ortamlarının öğrenen özelliklerine uygun tasarlanması önemlidir. Çalışmaların nicel desenin yanı sıra nitel desenlerle de desteklenmesi araştırma deseninden kaynaklı sınırlılıkları azaltacağından çalışmanın daha güçlü olması açısından da önemlidir. Bu kapsamda araştırma deseninde yapılacak farklılar sunulacak verilerin niteliğini arttıracaktır. İleride yapılacak olan araştırmalarda da farklı değişkenlere odaklanılarak daha etkili ortamların sunulabilmesi için sonuçlar paylaşılabilir. 


\section{Summary}

Purpose and Significance: Online learning has been offering practical, efficient and effective solutions for reaching out big groups of learners in terms of learning and education. These environments consist many people who have very distinct properties from each other. Even if the presented content has been diversified, mostly it is designed for the ideal user. However, every person has some individual characteristics, which can be natal and acquired in time. These individual differences are important in order to provide effective learning experiences in learning environments. In this context when the e-learning studies analyzed it can be seen that there are several studies, which focused on individual differences. Every study has a different point of view for individual differences. Personality traits, cognitive characteristics, and prior learning experiences can be examples of this situation. The main objective of this study is conducting a systematic review with the aim of identifying which individual differences studied and their relationships with dependent variables between 2010-2017 years.

Methods: In this study, systematic review method was used to examine the research conducted in the field of online learning in terms of individual differences. The systematic review method includes data collection in the framework of previously defined criteria in order to answer research questions. In this context, researcher defined review criteria (keywords, selection criteria, method) and conducted review process on ISI Web of Knowledge, Ebscohost, Scopus, and JSTOR online databases. The studies published only in refereed journals have been included in the study and gray literature sources, technical reports, institutional reports, study analyzes have not included. Also, non-research articles (such as meta-analysis, systematic review, and scale development) were not included in this review. According to search results, 38 research articles have been included in this study. In the study international databases were used, thus nonEnglish studies were not included. Selected keywords for review process are: "individual differences"/"learner characteristic" + "e-learning", "web based learning", "online learning", and "distance education".

Results: In the context of systematic review it has been found that quantitative studies are much more preferred than mixed studies. According to the analysis 37 of these studies conducted with quantitative research design, and 1 of them conducted mixed research design. In the context of the second research question, it was examined which independent variables examined the individual differences in the research. Gender, personality traits, prior knowledge, cognitive styles, learning styles, age, self-efficacy and pre-experience are the most frequently used variables in these studies. Academic achievement is the most frequently used variable among the dependent variables included in the studies examined. Satisfaction, e-learning acceptance, perception, anxiety variables follow the academic achievement variable. These studies mostly conducted in the US and Taiwan.

Discussion and Conclusions: Prominent results show that cognitive differences have been worked less in comparison to the other variables in terms of individual differences perspective. In the context of individual differences; the academic achievement is the 
most frequently used variable, and this result is not a surprising one. Academic achievement can be always one of the variables expected to be analyzed because every intervention in the learning environment is the basis of each research, providing better learning experiences, and being able to create more effective learning. It can be expected that more effective results will be obtained if the learning environments and processes are carefully considered in the data obtained from the researches on this academic achievement variable. Cognitive styles and learning styles are also frequently used in e-learning researches. Despite the concentration of criticisms on learning styles, the researches still show that the effects of this variable have been researched. It is seen that cognitive-based differences such as memory, attention, and spatial skills are less studied in comparison to the other variables such as gender, personality traits and age. Designing environments according to a single ideal user model can't provide the same benefits for individuals with different characteristics, because one doesn't fit all. For this reason, it is important that the variation arising from these cognitive characteristics of the individuals is known and designed according to the learning characteristics of learning environments. It is also important that supporting the researches by qualitative methods as well as quantitative methods, because it reduces the limitations each of the research patterns, so more robust results can show up. In this context, differences in the research design will increase the quality of the data to be presented. Future research can focus on different variables and shared results can help to improve more effective environments. 


\section{Kaynakça ${ }^{1}$}

Accuray Research LLP. (2017). Global e-learning market analysis \& trends - Industry forecast to 2025. Retrieved from https://www.researchandmarkets. com/ research/qgq5vf/global_elearning.

*Al-Dujaily, A., Kim, J., \& Ryu, H. (2013). Am i extravert or introvert? Considering the personality effect toward e-learning system. Educational Technology \& Society, 16(3), 14-27.

*Alhajri, R. A., Counsell, S., \& Liu, X. (2013). Investigating attributes affecting the performance of WBI users. Computers \& Education, 68, 117-128. doi:10.1016/j.compedu.2013.05.003

*Chen, L. H. (2010). Web-based learning programs: Use by learners with various cognitive styles. Computers \& Education, 54(4), 1028-1035. doi:10.1016/j.compedu.2009.10.008

*Chen, Y. C. (2015). Linking learning styles and learning on mobile Facebook. International Review of Research in Open and Distance Learning, 16(2), 94114.

Cho, M.H., Demei, S., \& Laffey, J. (2010). Relationships between self-regulation and social experiences in asynchronous online learning environments. Journal of Interactive Learning Research, 21(3), 297-316.

Clay, M. N., Rowland, S., \& Packard, A. (2009). Improving undergraduate online retention through gated advisement and redundant communication. Journal of College Student Retention: Research, Theory and Practice, 10(1), 93-102.

*Clewley, N., Chen, S. Y., \& Liu, X. (2011). Mining learning preferences in web-based instruction: holists vs. serialists. Educational Technology \& Society, 14 (4), 266-277.

*Cochran, J. D., Campbell, S. M., Baker, H. M., \& Leeds, E. M. (2014). The role of student characteristics in predicting retention in online courses. Research in Higher Education, 55(1), 27-48.

Deborah, L. J., Baskaran, R., \& Kannan, A. (2014). Learning styles assessment and theoretical origin in an e-learning scenario: A survey. Artificial Intelligence Review, 42(4), 801-819.

*Ekwunife-Orakwue, K. C. V., \& Tian-Lih, T. (2014). The impact of transactional distance dialogic interactions on student learning outcomes in online and blended environments. Computers \& Education, 78, 414-427. doi:10.1016/j. compedu.2014.06.011

*Fan-Ray, K., Gwo-Jen, H., Szu-Chuang, C., \& Sherry, Y. C. (2012). A cognitive apprenticeship approach to facilitating web-based collaborative problem solving. Journal of Educational Technology \& Society, 15(4), 319-331.

Felder, R. M., \& Silverman, L. K. (1988). Learning styles and teaching styles in engineering education. Engineering Education, 78(7), 674-681.

\footnotetext{
${ }^{1} \mathrm{Bu}$ araştırmaya dahil edilen çalışmalar Kaynakça'da * ile belirtilmiştir. 
*Flores, R., Ari, F., Inan, F. A., \& Arslan-Ari, I. (2012). The impact of adapting content for students with individual differences. Educational Technology \& Society, 15(3), 251-261.

*Ghorbani, F., \& Montazer, G. A. (2015). E-learners' personality identifying using their network behaviors. Computers in Human Behavior, 51(PA), 42-52. doi:10.1016/j.chb.2015.04.043

Gonzalez-Gomez, F., Guardiola, J., Rodriguez, O. M., \& Alonso, M. A. M. (2012). Gender differences in e-learning satisfaction. Computers \& Education, 58(1), 283-290. doi:10.1016/j.compedu.2011.08.017

*Gökçearslan, Ş., \& Alper, A. (2015). The effect of locus of control on learners' sense of community and academic success in the context of online learning communities. Internet and Higher Education, 27, 64-73. doi:10.1016/j.iheduc.2015.06.003

*Granić, A., \& Adams, R. (2011). User sensitive research in e-learning: Exploring the role of individual user characteristics. Universal Access in the Information Society, 10(3), 307-318. doi:10.1007/s10209-010-0207-7

*Grieve, R., Kemp, N., Norris, K., \& Padgett, C. R. (2017). Push or pull? Unpacking the social compensation hypothesis of Internet use in an educational context. Computers \& Education, 109, 1-10. doi:10.1016/j.compedu.2017.02.008

Higgins, JPT, \& Green, S. (2011). Cochrane handbook for systematic reviews of interventions version 5.1.0 [updated March 2011]. The Cochrane Collaboration. Retrieved from http://handbook.cochrane.org.

*Hsia, J. W., Chang, C. C., \& Tseng, A. H. (2014). Effects of individuals' locus of control and computer self-efficacy on their e-learning acceptance in high-tech companies. Behaviour and Information Technology, 33(1), 51-64. doi:10.1080/0144929X.2012.702284

*IAl-Azawei, A., Parslow, P., \& Lundqvist, K. (2017). Investigating the effect of learning styles in a blended e-learning system: An extension of the technology acceptance model (TAM). Australasian Journal of Educational Technology, 33(2), 1-23. doi:10.14742/ajet.2741

*Ilgaz, H., Altun, A., \& Aşkar, P. (2014). The effect of sustained attention level and contextual cueing on implicit memory performance for e-learning environments. Computers in Human Behavior, 39. 1-7. doi:10.1016/j.chb.2014.06.008

Ivankova, N. V., \& Stick, S. L. (2007). Students' persistence in a distributed doctoral program in educational leadership in higher education: A mixed methods study. Research in Higher Education, 48(1), 93-135.

*Jashapara, A., \& Tai, W. C. (2011). Knowledge mobilization through e-learning systems: understanding the mediating roles of self-efficacy and anxiety on perceptions of ease of use. Information Systems Management, 28(1), 71-83. doi:10.1080/10580530.2011.536115

*Jraidi, I., \& Frasson, C. (2013). Student's uncertainty modeling through a multimodal sensor-based approach. Educational Technology \& Society, 16 (1), 219-230.

*Kanar, A. M., \& Bell, B. S. (2013). Guiding learners through technology-based instruction: The effects of adaptive guidance design and individual differences 
on learning over time. Journal of Educational Psychology, 105(4), 1067-1081.

*Keller, H., \& Karau, S. J. (2013). The importance of personality in students' perceptions of the online learning experience. Computers in Human Behavior, 29(6), 2494-2500. doi:10.1016/j.chb.2013.06.007

Kirschner, P. A. \& van Merriënboer, J.J.G. (2013). Do learners really know best? Urban legends in education. Educational Psychologist, 48(3), 169-183. doi: 10.1080/00461520.2013.804395

*Kizilcec, R. F., Perez-Sanagustin, M., \& Maldonado, J. J. (2017). Self-regulated learning strategies predict learner behavior and goal attainment in Massive Open Online Courses. Computers \& Education, 104, 18-33. doi:10.1016/j.compedu.2016.10.001

Kolb, D. A. (1984). Experiential learning. Englewood Cliffs, NJ: Prentice Hall.

Lee, Y., \& Choi, J. (2011). A review of online course dropout research: implications for practice and future research. Educational Technology Research and Development, 59(5), 593-618. doi:10.1007/s11423-010-9177-y

*Lee, D. Y., \& Shin, D.-H. (2011). Effects of spatial ability and richness of motion cue on learning in mechanically complex domain. Computers in Human Behavior, 27(5), 1665-1674. doi:10.1016/j.chb.2011.02.005

Levy, Y. (2007). Comparing dropouts and persistence in e-learning courses. Computers \& Education, 48(2), 185-204. doi:10.1016/j.compedu.2004.12.004

*Lin, P.-C., Hou, H.-T., Wang, S.-M., \& Chang, K.-E. (2013). Analyzing knowledge dimensions and cognitive process of a project-based online discussion instructional activity using Facebook in an adult and continuing education course. Computers \& Education, 60(1), 110-121. doi: 10.1016/j.compedu.2012.07.017

*López-Vargas, O., Ibáñez-Ibáñez, J., \& Racines-Prada, O. (2017). Students metacognition and cognitive style and their effect on cognitive load and learning achievement. Journal of Educational Technology \& Society, 20(3), 145-157.

*Lu, H.-P., \& Chiou, M.-J. (2010). The impact of individual differences on e-learning system satisfaction: A contingency approach. British Journal of Educational Technology, 41(2), 307-323. doi:10.1111/j.1467-8535.2009.00937.x

McCrae, R. R., \& Costa, P. T. (1987). Validation of the five-factor model of personality across instruments and observers. Journal of Personality and Social Psychology, 52, 81-90.

McCrae, R. R. and John, O. P. (1992), An introduction to the five-factor model and its applications. Journal of Personality, 60, 175-215. doi:10.1111/j.14676494.1992.tb00970.x

Nawrot, I., \& Doucet, A. (2014). Building engagement for MOOC students: introducing support for time management on online learning platforms. Proceedings of the Companion Publication of the 23rd International Conference on World Wide Web Companion, 1077-1082.

Norwich, B. (2002). Education, inclusion and individual differences: Recognising and resolving dilemmas. British Journal of Educational Studies, 50(4), 482-502. doi:10.1111/1467-8527.t01-1-00215 
*Orvis, K. A., Brusso, R. C., Wasserman, M. E., \& Fisher, S. L. (2011). E-nabled for elearning? The moderating role of personality in determining the optimal degree of learner control in an e-learning environment. Human Performance, 24(1), 6078. doi:10.1080/08959285.2010.530633

Park, J.Y., \& Choi, H.J. (2009). Factors influencing adult learners' decision to drop out or persist in online learning. Journal of Educational Technology \& Society, 12(4), 207-217.

Poll, K., Widen, J., \& Weller, S. (2014). Six instructional best practices for online engagement and retention. Journal of Online Doctoral Education, 1(1), 56- 72

Price, L. (2004). Individual differences in learning: Cognitive control, cognitive style, and learning style. Educational Psychology, 24(5), 681-698. doi: 10.1080/0144341042000262971

*Raes, A., Schellens, T., De Wever, B., \& Vanderhoven, E. (2012). Scaffolding information problem solving in web-based collaborative inquiry learning. Computers \& Education, 59(1), 82-94. doi:10.1016/j.compedu.2011.11.010

*Randler, C., Horzum, M. B., \& Vollmer, C. (2014). The influence of personality and chronotype on distance learning willingness and anxiety among vocational high school students in Turkey. International Review of Research in Open and Distance Learning, 15(6), 93-110.

*Ren, Y., Dai, Z.-X., Zhao, X.-H., Fei, M.-M., \& Gan, W.-T. (2017). Exploring an online course applicability assessment to assist learners in course selection and learning effectiveness improving in e-learning. Learning \& Individual Differences, 60, 56-62. doi:10.1016/j.lindif.2017.09.002

Riding, R. (2005). Individual differences and educational performance. Educational Psychology, 25(6), 659-672. doi:10.1080/01443410500344712

Rovai, A. P. (2001). Classroom community at a distance: A comparative analysis of two ALN-based university programs. The Internet and Higher Education, 4(2), 105118.

*Sabah, N. M. (2016). Exploring students' awareness and perceptions: Influencing factors and individual differences driving m-learning adoption. Computers in Human Behavior, 65, 522-533. doi:10.1016/j.chb.2016.09.009

*Sanchez-Franco, M. J., Peral-Peral, B., \& Villarejo-Ramos, A. F. (2014). Users' intrinsic and extrinsic drivers to use a web-based educational environment. Computers \& Education, 74, 81-97. doi:10.1016/j.compedu.2014.02.001

*Sansone, C., Fraughton, T., Zachary, J. L., Butner, J., \& Heiner, C. (2011). Selfregulation of motivation when learning online: the importance of who, why and how. Educational Technology Research and Development, 59(2), 199-212.

Schaeffer, C. E., \& Konetes, G. D. (2010). Impact of learner engagement on attrition rates and student success in online learning. International Journal of Instructional Technology \& Distance Learning, 7(5), 3-9.

*Sheng-Wen, H. (2011). Effects of cognitive styles on an MSN virtual learning companion system as an adjunct to classroom instructions. Journal of Educational Technology \& Society, 14(2), 161-174.

Sun, J. C.-Y., \& Rueda, R. (2012). Situational interest, computer self-efficacy and self- 
regulation: Their impact on student engagement in distance education. British Journal of Educational Technology, 43(2). 191-204. doi:10.1111/j.14678535.2010.01157.x

*Tarhini, A., Hone, K., \& Liu, X. (2014). The effects of individual differences on elearning users' behaviour in developing countries: A structural equation model. Computers in Human Behavior, 41, 153-163. doi:10.1016/j.chb.2014.09.020

*Tempelaar, D. T., Niculescu, A., Rienties, B., Gijselaers, W. H., \& Giesbers, B. (2012). How achievement emotions impact students' decisions for online learning, and what precedes those emotions. Internet and Higher Education, 15(3), 161-169. doi: 10.1016/j.iheduc.2011.10.003

*Walkowiak, S., Foulsham, T., \& Eardley, A. F. (2015). Individual differences and personality correlates of navigational performance in the virtual route learning task. Computers in Human Behavior, 45, 402-410. doi:10.1016/j.chb.2014.12.041

Witkin, H. A., Moore, C. A., Goodenough, D. R., \& Cox, P. W. (1977). Field dependent and field-independent cognitive styles and their educational implications. Review of Educational Research, 47, 1-64.

*Wu, Y. (2016). Factors impacting students' online learning experience in a learnercentred course. Journal of Computer Assisted Learning, 32(5), 416-429. doi:10.1111/jcal.12142 